\title{
Do Body Composition and Physiological Parameters Measured in the Laboratory Have Predictive Value for Cycling Performance?
}

\author{
Iva Jurov ${ }^{1}$, Radoje Milic ${ }^{1}$ and Samo Rauter ${ }^{1}$ \\ 'University of Ljubljana, Faculty of Sport, Ljubljana, Slovenia
}

\begin{abstract}
Physiological parameters measured in the laboratory are used in cycling for analysing changes in performance, adjusting training regimes, and helping with predicting future performance. Some parameters are known to have better predictive credibility than others. In this study, we aimed to find the parameters that influenced performance in the same cyclists in two consecutive years. We gathered the scoring results of 29 competitive young cyclists $(18.45 \pm 2.23$ years old $)$ in various age categories and their physiological parameters. The racing results were obtained from both the national and international levels. From measurements of change in peak power output, body composition and gas exchange, this study showed that the negative change in the percentage of body fat positively correlated with all-year scoring results in male cyclists of different ages. No other correlations were found. This research amplifies the importance of body composition in cycling and suggests further research is needed on the influence of body composition on cycling performance.
\end{abstract}

Keywords: cycling, performance, body composition, power output

\section{Introduction}

Cycling is an endurance sport discipline in which physiological parameters are often used for assessing performance (E.W. Faria, Parker, \& I.E. Faria, 2005a; Impellizzeri, Marcora, Rampinini, Mognoni, \& Sassi, 2005; Tanner, \& Gore, 2013). Various protocols can be used in incremental testing for gathering performance-related parameters. Usually, intensity is increased between 10 and $30 \mathrm{~W}$ every 30-60 s (Amann, Subudhi, \& Foster, 2004). Parameters measured during incremental test include maximal oxygen uptake $\left(\mathrm{VO}_{2 \max }\right)$, peak power output (PPO), lactate values, ventilation (VE), gas exchange $\left(\mathrm{VO}_{2}\right.$ and $\left.\mathrm{VCO}_{2}\right)$ and heart rate (HR). Anthropometric measurements provide additional data widely used today for cycling performance assessment, such as $\mathrm{PPO}$ and $\mathrm{VO}_{2 \max }$ values expressed relative to body mass $(\mathrm{W} / \mathrm{kg}$ and $\mathrm{ml} / \mathrm{min} / \mathrm{kg}$ ).
This is because cyclists have to overcome gravitational forces in relatively long periods. Body mass (BM) is an essential parameter in cycling (Maciejczyk, Wiecek, Szymura, Szygula, $\&$ Brown, 2015), and it has long been known that a limit of $>6 \mathrm{~W} / \mathrm{kg}$ can be used as an assessment tool for good racing outcomes (Palmer, Borghouts, Noakes, \& Hawley, 1999). Another parameter PPO normalized to fat-free mass (PPO/ FFM) has been introduced as having a more critical influence on PPO in cycling than PPO/BM has (Maciejczyk et al., 2015). BM increase resulting from increased body fat percentage (BF) has been shown to negatively affect PPO (Maciejczyk et al., 2015). Another parameter in cycling and other endurance disciplines known to be associated with aerobic capacity is $\mathrm{VO}_{2 \max } / \mathrm{BM}$. Elite cyclists exhibit values of $70-75 \mathrm{ml} / \mathrm{kg} / \mathrm{min}$ (Lucia, Hoyos, Perez, Santalla, \& Chicharro, 2002) whereas

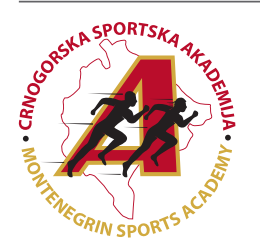

Correspondence:

I. Jurov, University of Ljubljana, Faculty of Sport, Gortanova 22, 1000 Ljubljana, Slovenia

E-mail: iva.jurov@fsp.uni-lj.si 
an average man can reach $35-40 \mathrm{ml} / \mathrm{min} / \mathrm{kg}$ (Guyton \& Hall, 2011). Although high $\mathrm{VO}_{2 \max } / \mathrm{BM}$ values can also be found amongst recreationally active cyclists, professionals have a greater cycling efficiency that enables them to perform better (Lucia et al., 2002).

Four parameters $\left(\mathrm{PPO} / \mathrm{BM}, \mathrm{PPO} / \mathrm{FFM}, \mathrm{VO}_{2 \max } / \mathrm{BM}, \mathrm{BF}\right)$ gathered with incremental cycling test and anthropometry were used in this study. We observed changes in these parameters in the same cyclists in two consecutive years (2015 and 2016) and compared these changes to the difference in the overall racing results in the two years. We hypothesized that an increase in $\mathrm{PPO} / \mathrm{BM}, \mathrm{PPO} / \mathrm{FFM}$ and $\mathrm{VO}_{2 \max } / \mathrm{BM}$ would elicit an increase in points gathered and a decrease in $\mathrm{BF}$ would cause an increase in scoring results.

\section{Methods}

Twenty-nine (29) cyclists $(18.45 \pm 2.23$ years old) participated in the study. They were measured twice in two consecutive years. For this study, data gathered before the competitive season were used (gathered from January to March). The study was approved by the institutional ethics committee.

\section{Anthropometry}

$\mathrm{BM}$ and body composition were assessed with bioelectrical impedance (Biospace InBody 720, Seoul, Korea). Body height was measured with an anthropometer (GPM, Siber Hegner \& Co., Switzerland, 2007).

\section{Incremental test}

Cyclists performed an incremental test on a Cyclus 2 ergometer (RBM Electronics, Leipzig, Germany) using their own bicycles. Two different protocols were used according to the cyclists' ages. Those under 17 years old performed $60+15$ $\mathrm{W}$ protocol (starting with $60 \mathrm{~W}$ in the first minute and adding $15 \mathrm{~W}$ every additional minute), and those of 17 years or older executed $100+20 \mathrm{~W}(100 \mathrm{~W}$ in the first minute and an increase in $20 \mathrm{~W}$ for every additional minute). During the test, a cadence of 60 or higher had to be maintained with a constant gear ratio. The incremental test is performed until exhaustion. Peak power had to be sustained for $60 \mathrm{~s}$ to be used. If only $30 \mathrm{~s}$ at peak power output were reached, one half of the performed power increment is added. Cyclists had to warm up $15 \mathrm{~min}$ before and rest $60 \mathrm{~s}$ before commencing the test.

\section{Gas exchange}

Ventilatory parameters were measured with V2 mask (Hans Rudolph, USA) of appropriate size and Quark CPET (Cosmed, Albano Laziale, Rome, Italy) with Quark 8.1. PC software support. Before commencing the test, we calibrated the machine $\left(\mathrm{O}_{2}\right.$ and $\mathrm{CO}_{2}$ analyser and air-flow device).

\section{Collecting data}

In the first round of testing, 62 male road cyclists met the criteria of having all laboratory measurements in two consecutive years. We excluded all who did not compete in at least 15 competitions of national level and internationally accredited competitions under the UCI (Union Cycliste Internationale). Due to changes in the cyclists' physical condition in different periods across the season, we used only the data gathered in the pre-season (from January to March). Lastly, seven additional cyclists were excluded as they were no longer active in competitive cycling. We suggest that their racing scores in the measured years might be influenced by other unknown factors, such as psychological factors and other detrimental factors that can be present at the end of an athlete's career. A total of 29 cyclists met all criteria.

Racing points were gathered throughout the competitive season from national and international levels. There is no official comparison system that would enable comparing the two levels. Thus, an unofficial system was used in this study, which is also used by national cycling managers when selecting national teams. They add national points to international points multiplied by two as the latter are more difficult to obtain.

\section{Data analysis}

Microsoft Office software was used for processing data. The analysis was performed with SPSS (version 25.0; SPSS, Inc., Chicago, USA). Descriptive statistics (average \pm SD) are used for representing data. Parameters of relative increase were used to compare the differences in all parameters and scoring results in two different years. We calculated them by subtracting the values in the second year from values in the first year and making this difference relative to the value in the first year ( $\mathrm{PPO} / \mathrm{BM}$ rel, $\left.\mathrm{PPO} / \mathrm{FFM}_{\text {rel' }}, \mathrm{VO}_{2 \max } / \mathrm{BM}_{\text {rel }}, \mathrm{BF}_{\text {rel }}, \mathrm{T}_{\text {rel }}\right)$ (Figure 1).

$$
\text { Trel }=\frac{\mathrm{T} \text { 2nd year }-\mathrm{T} \text { 1st year }}{T \text { 1st year }}
$$

Figure 1. The equation for calculating the parameter of relative increase for scoring results

Multiple regression was used. A normal distribution assumption was not met in $\mathrm{T}$ rel so we used logarithmic transformation (by adding a constant to all of the data to make positive numbers). According to Berry (1993), we confirmed all assumptions.

\section{Results}

The main characteristics of cyclists are represented in Table 1 . The descriptive data of the cyclists were gathered from testing in the $2^{\text {nd }}$ year.

Table 1. Main characteristics of cyclists gathered in the second year: age, body composition, and physiological parameters

\begin{tabular}{cc}
\hline variable & Mean \pm SD \\
\hline age & $18.45 \pm 2.23$ \\
$\mathrm{BM}(\mathrm{kg})$ & $70.68 \pm 6.66$ \\
$\mathrm{BF}(\%)$ & $9.2 \pm 2.4$ \\
$\mathrm{VO}_{2 \max } / \mathrm{kg}(\mathrm{ml} / \mathrm{min} / \mathrm{kg})$ & $64.84 \pm 4.81$ \\
$\mathrm{PPO} / \mathrm{BM}(\mathrm{W} / \mathrm{kg})$ & $6.19 \pm 0.42$ \\
$\mathrm{PPO} / \mathrm{FFM}(\mathrm{W} / \mathrm{kg})$ & $3.2 \pm 0.23$ \\
\hline
\end{tabular}


For the study, we compared the differences in physiological parameters from the tests and scoring results in two different years. The results of multiple regression are shown in Table 2.

Table 2. The results of multiple regression analysis

\begin{tabular}{|c|c|c|c|c|}
\hline & \multirow[t]{2}{*}{ Model } & \multicolumn{2}{|c|}{$\begin{array}{l}\text { Unstandardized } \\
\text { Coefficients }\end{array}$} & \multirow{2}{*}{$\begin{array}{c}\begin{array}{c}\text { Standardized } \\
\text { Coefficients }\end{array} \\
\text { Beta } \beta\end{array}$} \\
\hline & & B & Std. Error & \\
\hline \multirow{2}{*}{1} & (Constant) & 0.06 & 0.07 & \\
\hline & $\mathrm{BF}_{\text {rel. }}$ & -1.4 & 0.36 & $-.60^{*}$ \\
\hline \multirow{5}{*}{2} & (Constant) & 0.12 & 0.13 & \\
\hline & $\mathrm{BF}_{\text {.rel. }}$ & -1.38 & 0.43 & $-.59 *$ \\
\hline & $\mathrm{VO}_{2 \max } / \mathrm{BM}_{\text {.rel. }}$ & 3.08 & 1.52 & 0.31 \\
\hline & $\mathrm{PPO} / \mathrm{BM}_{\text {rel. }}$ & 0.36 & 0.43 & 0.13 \\
\hline & PPO/FFM & -0.44 & 1.82 & -0.05 \\
\hline
\end{tabular}

The biggest correlation was found in $\mathrm{BF}_{\text {rel }}(-0.597, \mathrm{p}<0.001)$, followed by $\mathrm{PPO} / \mathrm{FFM}$ rel $(0.353, \mathrm{p}<0.05)$ and $\mathrm{VO}_{2 \max } / \mathrm{BM}_{\mathrm{re}}$ (0.342, $\mathrm{p}<0.001)$. Model 1, using just $\mathrm{BF}_{\text {rel }}$ explained $35.7 \%$ of the variability of $\mathrm{T}_{\text {rel }}$ whereas Model 2, using $\mathrm{BF}{ }_{\text {rel }} \mathrm{W} / \mathrm{kg}_{\text {rel' }}$ $\mathrm{PPO} / \mathrm{FFM}_{\text {rel }}$, and $\mathrm{VO}_{2 \max } / \mathrm{BM}_{\text {rel }}$ added only $9.9 \%$ to the variability. The model summary is presented in Table 3.

Table 3. Model summary presented of the multiple regression analysis

\begin{tabular}{|c|c|c|c|c|c|c|c|c|c|}
\hline Model & $\mathrm{R}$ & $\begin{array}{c}\mathrm{R} \\
\text { Square }\end{array}$ & $\begin{array}{l}\text { Adjusted } \\
\text { R Square }\end{array}$ & $\begin{array}{c}\text { R } \\
\text { Square } \\
\text { Change }\end{array}$ & $\begin{array}{c}\mathrm{F} \\
\text { Change }\end{array}$ & df1 & $\mathrm{df} 2$ & $\begin{array}{c}\text { Sig. F } \\
\text { Change }\end{array}$ & $\begin{array}{l}\text { Durbin- } \\
\text { Watson }\end{array}$ \\
\hline 1 & $.597 a$ & 0.357 & 0.333 & 0.357 & 14.988 & 1 & 27 & 0.001 & \\
\hline 2 & $.676 b$ & 0.456 & 0.366 & 0.099 & 1.462 & 3 & 24 & 0.250 & 1.859 \\
\hline
\end{tabular}

\section{Discussion}

This study was carried out on young top-level cyclists. It compared changes in physiological markers and body composition in the same participants across two consecutive competitive years. It has shown that, of the measured parameters, only changes of BF had an important impact on racing result at the end of the year $(\mathrm{t}(29)=-1.402, \mathrm{p}<0.01)$. If the BF was lower, the result at the end of the year was better. These results suggest that in competitive cycling not only BM is important, but body composition also has a role. More importantly, in young top-level cyclists, reducing BF values could have A positive effect on performance. This is in accordance with a recent study that found a negative correlation between $\mathrm{BF}$ and PPO in cycling (Maciejczyk et al., 2015). The authors suggested avoiding a surfeit of BF to improve cycling anaerobic power. However, a study also showed that increased BM diminished $\mathrm{VO}_{2 \max } / \mathrm{BM}$ regardless of body composition (Maciejczyk et al., 2014). In this study, a change in $\mathrm{VO}_{2 \max } / \mathrm{BM}$ did not correlate with changes in racing results. According to Faria et al. (Faria, Parker, \& Faria, 2005b), $\mathrm{VO}_{2 \max }$ has limited predictive credibility when cyclists of homogenous aerobic capabilities are compared. This is consistent with our results, as our participants were homogenous in aerobic capacity $\left(\mathrm{VO}_{2 \max } / \mathrm{BM} 64.84 \pm\right.$ $4.82 \mathrm{ml} / \mathrm{min} / \mathrm{kg}$ ). However, this is not in accordance with studies showing that relative $\mathrm{VO}_{2 \max }$ is an important performance predictor (MacRae, 2006; Novak \& Dascombe, 2014; Pfeiffer, Harder, Landis, Barber, \& Harper, 1993; Ramana, Surya, Sudhakar, \& Balakrishna, 2014). This could imply that cyclists should not focus only on lowering BM or maintaining relatively low BM when trying to increase performance. What their $\mathrm{BF}$ is might also be important. Male athletes might reduce their $\mathrm{BF}$ to as low as $1 \%$ with no evident medical consequences
(Johnson, Powers, \& Dick, 1999). However, values as low as these are questionable for having only good outcomes for all athletes and could have a negative impact on performance as suggested by research that has been done in body composition in leanness-demanding sports (Meyer et al., 2013).

In addition, the time needed to reduce BF is probably significant. Studies assessing low energy availability point out that cutting weight too quickly negatively affects performance (Mooses \& Hackney, 2017; Tornberg et al., 2017) and that there should be a gradual BM change allowing the fat-free mass to be lowered as little as possible in this process. In this study, we did not assess ways of weight cycling in participants so we cannot suggest if the timing of cutting BF has any impact. However, from other research done in low energy availability, we know BF values can be much lower in male than in female athletes without evident health damage. Nevertheless, there is probably an individual threshold in men and women at which maintaining low $\mathrm{BF}$ values is not possible with sustaining optimal performance. This could suggest $\mathrm{BF}$ annual changes are also needed in competitive cycling, with BF values being the lowest in the racing period and slightly increased in recovery and preparation period for enabling good recovery and hormonal balance. Another problem could be a BF overshoot after drastic reductions, as seen in bodybuilders (Fagerberg, 2018). As suggested by Fagerberg, a more tempered approach to BF management could be more optimal for bodybuilders. We wonder if $\mathrm{BF}$ overshoot after drastic reductions in $\mathrm{BF}$ values is also present in cycling. This would certainly reduce performance. More research is needed, especially in younger cyclists for whom drastically low BF values could also have a negative impact on growth and development.

Finally, changes in $\mathrm{PPO} / \mathrm{BM}$ and $\mathrm{PPO} / \mathrm{FFM}$ did not sig- 
nificantly influence racing results although there were significant changes in values across two years $(t=-3.69, p<0.001$ and $\mathrm{t}=5.32, \mathrm{p}<0.000)$. There are some limitations to this study. According to the cyclists' ages, two different protocols were used in an incremental cycling test. PPO could be influenced by these two different approaches, as lower PPO is achieved in longer protocols (Bentley, Newell, \& Bishop, 2007). This could interfere with our $\mathrm{PPO} / \mathrm{BM}$ and $\mathrm{PPO} / \mathrm{FFM}$ measurements.

\section{Acknowledgements}

There are no acknowledgements.

\section{Conflict of Interest}

The authors declare that there are no conflicts of interest.

Received: 21 October 2019| Accepted: 17 December 2019 | Published: 01 February 2020

\section{References}

Amann, M., Subudhi, A., \& Foster, C. (2004). Influence of Testing Protocol on Ventilatory Thresholds and Cycling Performance. Medicine and Science in Sports and Exercise, 36(4), 613-622. https://doi.org/10.1249/01. MSS.0000122076.21804.10

Bentley, D.J., Newell, J., \& Bishop, D. (2007). Incremental exercise test design and analysis: Implications for performance diagnostics in endurance athletes. Sports Medicine, 37(7), 575-586. https://doi. org/10.2165/00007256-200737070-00002

Berry, W. D. (1993). Sage university papers series. Quantitative applications in the social sciences, Vol. 92. Understanding regression assumptions. Sage Publications, Inc.

Fagerberg, P. (2018). Negative Consequences of Low Energy Availability in Natural Male Bodybuilding: A Review. International Journal of Sport Nutrition and Exercise Metabolism, 28(4), 385-402.

Faria, E.W., Parker, D.L., \& Faria, I.E. (2005a). The science of cycling: factors affecting performance - part 2. Sports Medicine (Auckland, N.Z.), 35(4), 313-337. https://doi.org/10.2165/00007256-200535040-00002

Faria, E.W., Parker, D.L., \& Faria, I.E. (2005b). The Science of Cycling. Sports Medicine, 35(4), 285-312.https://doi.org/10.2165/00007256-200535040-00003

Guyton, A., \& Hall, J.E. (2011). Textbook of Medical Physiology, 12th Ed.

Impellizzeri, F.M., Marcora, S.M., Rampinini, E., Mognoni, P., \& Sassi, A. (2005). Correlations between physiological variables and performance in high level cross country off road cyclists. British Journal of Sports Medicine, 39(10), 747-751. https://doi.org/10.1136/bjsm.2004.017236

Johnson, C., Powers, P.S., \& Dick, R. (1999). Athletes and eating disorders: The National Collegiate Athletic Association study. International Journal of Eating Disorders, 26(2), 179-188. https://doi.org/10.1002/(SICI)1098108X(199909)26:2<179::AID-EAT7>3.0.CO;2-Z

Lucia, A., Hoyos, J., Perez, M., Santalla, A., \& Chicharro, J.L. (2002). Inverse relationship between $\mathrm{VO}_{2 \max }$ and economy/efficiency in world-class cyclists. Medicine \& Science in Sports \& Exercise, 34(12), 2079-2084. https://doi.org/10.1111/j.1365-294X.2004.02214.x
Secondly, it would be better to use only cyclists competing at the international level, as their scoring results could be compared more accurately. This was not possible in our study, as the number of participants would be too small. Further research on body composition effect on cycling performance would be beneficial as this study shows that BF could affect cycling performance in young top-level cyclists.

Maciejczyk, M., Wiecek, M., Szymura, J., Szygula, Z., \& Brown, L.E. (2015). Influence of Increased Body Mass and Body Composition on Cycling Anaerobic Power. The Journal of Strength and Conditioning Research, 29(1), 58-65.

Maciejczyk, M., Więcek, M., Szymura, J., Szyguła, Z., Wiecha, S., \& Cempla, J. (2014). The influence of increased body fat or lean body mass on aerobic performance. PLOS ONE, 9(4), 0-5. https://doi.org/10.1371/ journal.pone.0095797

MacRae, H.S.-H. (2006). Does Laboratory Testing Have Predictive and Practical Value for Cycling Performance? International Journal of Sports Science \& Coaching, 1(4), 389-397. https://doi.org/10.1260/174795406779367657

Meyer, N.L., Sundgot-Borgen, J., Lohman, T.G., Ackland, T.R., Stewart, A.D. Maughan, R.J., ... Müller, W. (2013). Body composition for health and performance: A survey of body composition assessment practice carried out by the ad hoc research working group on body composition, health and performance under the auspices of the IOC medical commission. British Journal of Sports Medicine, 47(16), 1044-1053. https://doi. org/10.1136/bjsports-2013-092561

Mooses, M., \& Hackney, A.C. (2017). Anthropometrics and Body Composition in East African Runners: Potential Impact on Performance. International Journal of Sports Physiology and Performance, 12(4), 422-430. https:// doi.org/10.1123/ijspp.2016-0408

Novak, A.R., \& Dascombe, B.J. (2014). Physiological and performance characteristics of road, mountain bike and BMX cyclists. Journal of Science and Cycling, 3(3), 9-16.

Palmer, G.S., Borghouts, L.B., Noakes, T.D., \& Hawley, J.A. (1999). Metabolic and performance responses to constant-load vs. variable-intensity exercise in trained cyclists. Journal of Applied Physiology (Bethesda, Md. : 1985), 87(3), 1186-1196. https://doi.org/10.1152/jappl.1999.87.3.1186

Pfeiffer, R.P., Harder, B.P., Landis, D., Barber, D., \& Harper, K. (1993). Correlating indices of aerobic capacity with performance in elite women road cyclists. Journal of Strength and Conditioning Research, 7(4), 201-205.

Ramana, V.Y., Surya, K.M., Sudhakar, R.S., \& Balakrishna, N. (2014). Effect of changes in body composition profile on $\mathrm{VO}_{2 \max }$ and maximal work performance in athlete. Journal of Exercise Physiology Online, 7(1), 34-39.

Tanner, R.K., \& Gore, C.J. (2013). Physiological Tests for Elite Athletes - second edition (A. I. of Sport, ed.).

Tornberg, Å.B., Melin, A., Koivula, F. M., Johansson, A., Skouby, S., Faber, J., \& Sjödin, A. (2017). Reduced Neuromuscular Performance in Amenorrheic Elite Endurance Athletes. In Medicine and Science in Sports and Exercise, 49(12), 2478-2485. https://doi.org/10.1249/MSS.0000000000001383 